\title{
Carbon dioxide vs. air insufflation in ileo-colonoscopy and in gastroscopy plus ileo-colonoscopy: a comparative study
}

\author{
María Fernández-Calderón ${ }^{1}$, Miguel Ángel Muñoz-Navas ${ }^{1}$, Juan Carrascosa-Gil²,

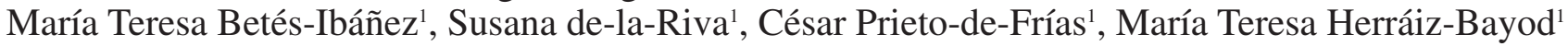 \\ and Cristina Carretero-Ribón ${ }^{1}$
}

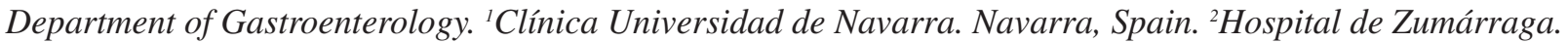
Guipúzcoa, Spain

\begin{abstract}
Introduction: insufflation with carbon dioxide $\left(\mathrm{CO}_{2}\right)$ during endoscopies compared to air is associated with a decrease in abdominal discomfort after the examination, because $\mathrm{CO}_{2}$ is readily absorbed through the small intestine and eliminated by the lungs.

Aim: the objective of this randomized clinical trial was to assess the effect of $\mathrm{CO}_{2}$ insufflation on pain and abdominal distension after an ileo-colonoscopy (I) and after an ileo-colonoscopy plus gastroscopy (I+G).

Material and methods: we included a total of 309 patients in the study and all endoscopies were performed under sedation with propofol. Two hundred fourteen patients underwent an I (132 with $\mathrm{CO}_{2} / 82$ with air) and 95 underwent an I+G (53 with $\mathrm{CO}_{2} / 42$ with air). Abdominal pain was studied at 10, 30 and 120 minutes of exploration and abdominal perimeter difference before and after the procedure.

Results: both in group I and in group I+G, the use of $\mathrm{CO}_{2}$ translated into an average of abdominal pain significantly lower $(\mathrm{p}<$ 0.05). Similarly, a smaller increase in waist circumference was found among group I and group I+G, in patients where $\mathrm{CO}_{2}$ was used ( $\mathrm{p}$ $<0.05)$.

Conclusion: the insufflation of $\mathrm{CO}_{2}$ instead of air during the performance of endoscopy significantly reduces the discomfort and abdominal pain after an ileo-colonoscopy and after a gastroscopy + ileo-colonoscopy.
\end{abstract}

Key words: $\mathrm{CO}_{2}$ insufflation. Endoscopy. Ileo-colonoscopy.

Fernández-Calderón M, Muñoz-Navas MA, Carrascosa-Gil J, Betés-Ibañez MT, De-la-Riva S, Prieto-de-Frías C, Herráiz-Bayod MT, Carretero-Ribón C. Carbon dioxide us. air insufflation in ileo-colonoscopy and in gastroscopy plus ileo-colonoscopy: a comparative study. Rev Esp Enferm Dig 2012; 104: 237-241.

Received: 10-11-11.

Accepted: 13-12-12.

Correspondence: María Fernández-Calderón. Departament of Gatroenterology. Clínica Universidad de Navarra. Av. Pío XII, 36. 31008 Pamplona, Navarra. Spain.

e-mail: mfdezcalderon@gmail.com

\section{INTRODUCTION}

In order to achieve an adequate visualization of the gastrointestinal mucosa during gastrointestinal endoscopy it is necessary to use gas insufflation. An average of $8 \mathrm{~L}$ of gas (air or $\mathrm{CO}_{2}$ ) has been estimated to be required during colonoscopy (1). Many patients manifest discomfort in the gastrointestinal tract associated with air insufflation. In the last years different methods have been evaluated to improve patient tolerance to endoscopy and most of these complaints have been solved with the widespread use of sedation. Other methods as $\mathrm{CO}_{2}$ insufflation have optimized tolerance.

Other authors have seen that the use of carbon dioxide $\left(\mathrm{CO}_{2}\right)$ during colonoscopy compared with room air, is associated with a decrease in pain after the procedure (2-7), because $\mathrm{CO}_{2}$ has the peculiarity that it is rapidly absorbed from the gastrointestinal tract and is eliminated through the respiratory tract (this does not occur with air, which can only be removed through a natural way), achieving a rapid decompression of the gastrointestinal tract. This feature would allow the reduction of pain during and after the examination, and also of the need for sedation or anesthesia and of the exploration and recovery times (8).

Since Rogers did a small study evaluating the safety of $\mathrm{CO}_{2}$ insufflation during endoscopy in 1974 (9), a number of authors have evaluated its use in gastrointestinal endoscopy: sigmoidoscopy (10), colonoscopy (1-7), ERCP $(11,12)$ and recently double-balloon enteroscopy $(13,14)$ and endoscopic submucosal dissection $(15,16)$.

The primary aim of this randomized blinded clinical trial was to assess the effect of $\mathrm{CO}_{2}$ insufflation on pain and abdominal distention after an ileo-colonoscopy (I) and after a gastroscopy plus ileo-colonoscopy ( $\mathrm{I}+\mathrm{G})$.

\section{MATERIAL AND METHODS}

A team of six doctor-nurse groups participated in the study (four of medical endoscopists with more than 10 years 
Table I. Baseline characteristics of both groups: mean (standard deviation)

\begin{tabular}{llll}
\hline & $\mathrm{CO}_{2}$ & Air & $p$ \\
\hline $\begin{array}{l}\text { Ileo-colonoscopy } \\
(n=214)\end{array}$ & $(n=132)$ & $(n=82)$ & \\
& & & \\
\hline Age (years) & $59(11.6)$ & $59(13.2)$ & 0.955 \\
Gender (M/F) & $79 / 53$ & $52 / 30$ & 0.666 \\
Weight (kg) & $75.11(14.5)$ & $77.12(16.2)$ & 0.348 \\
Height (cm) & $168.10(8.9)$ & $168.09(9.3)$ & 0.992 \\
BMl (kg/m²) & $26.4(4.1)$ & $27.1(4.6)$ & 0.263 \\
Propofol (mg) & $292.75(113.5)$ & $292.77(115.2)$ & 0.999 \\
& & & \\
\hline lleo-colonoscopy + & $(n=53)$ & $(n=42)$ & $p$ \\
gastroscopy $(n=95)$ & & & \\
\hline Age (years) & & $54(12.9)$ & 0.852 \\
Gender (M/F) & $55(14.4)$ & $22 / 20$ & 0.296 \\
Weight (kg) & $34 / 19$ & $74.98(15.1)$ & 0.904 \\
Height (cm) & $74.60(15.5)$ & $166.24(13.6)$ & 0.221 \\
BMl (kg/m²) & $169.08(8.7)$ & $26.5(4.64)$ & 0.638 \\
Propofol (mg) & $26.1(5.08)$ & $362.89(135.4)$ & 0.406 \\
\hline & $385(108.6)$ & &
\end{tabular}

of experience). We included a total of 309 patients who were undergoing a colonoscopy or gastroscopy plus colonoscopy. All patients signed, before the randomization, a specific informed consent for the study, which was approved by the hospital ethics committee. Exclusion criteria were: patients with a history of: abdominal surgery, inflammatory bowel disease, irritable bowel syndrome, severe chronic obstructive pulmonary disease or age over 80 or under 18 years old.

Of 309 patients, 214 (69.3\%) underwent an I (132 were randomized to $\mathrm{CO}_{2}$ insufflation and 82 to air) and 95 $(30.7 \%)$ underwent an $\mathrm{I}+\mathrm{G}\left(53 \mathrm{CO}_{2} / 42\right.$ air $)$. All procedures were performed under sedation with propofol, administrated by bolus or by infusion pump controlled by the anesthetist. We used a $\mathrm{CO}_{2}$ insufflator Olympus UCR (Endoscopic $\mathrm{CO}_{2}$ Regulation Unit).

The study was done by filling a questionnaire which contained 20 variables: age, gender, body mass index, weight, height, type of endoscope used, abdominal circumference before and after the examination, doctor-nurse team, type of bowel preparation, cleaning of the colon, duration of exploration, polypectomy, presence or absence of diverticula, the necessity or not to modify the stiffness of the endoscope, the need or not of manual pressure required for advancing the scope, propofol dose given, the need to pullback the scope or mobilize the patient for the procedure and tolerance to the test as abdominal pain.

Once the baseline characteristics of the patients were homogeneous, we specifically studied the following variables: abdominal pain, measured by visual analog scale (1 no-pain/10 worst pain) after 10 minutes, at discharge

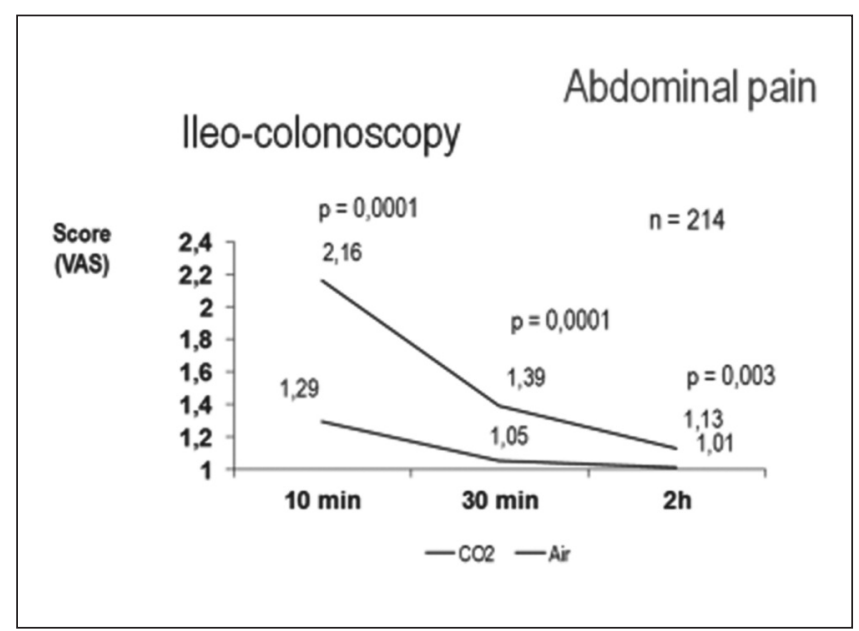

Fig. 1. Abdominal pain in the ileo-colonoscopy group.

from the endoscopy unit (approximately 30 minutes) and 2 hours after by telephone contact; and second, the abdominal circumference difference before and immediately after the procedure, always measured at periumbilical level by the same nurse, who did not know which type of gas was used.

\section{Statistical analysis}

We used a parametric test (Student $t$ test) for statistical analysis because the variables followed a normal distribution and we used the statistical program SPSS 13.0. Differences were considered significant between groups when $\mathrm{p}$ was less than 0.05 .

\section{RESULTS}

The 4 groups were similar in age, gender, weight, height, BMI and dose of propofol (Table I). There were no differences in the type of bowel preparation, cleansing, duration of exploration, performing polypectomies, presence of diverticula or need to perform various maneuvers to advance the endoscope.

Considering patients who underwent an ileocolonoscopy, at 10 minutes the score on the visual analog scale was an average of 1.29 in the $\mathrm{CO}_{2}$ group vs. 2.16 in the room air group; at 30 minutes, an average of $1.05 \mathrm{vs}$. 1.39 respectively; and at 120 minutes, an average of 1.01 vs. 1.13 respectively. All differences were statistically significant. It also showed that, although the differences were greater at the end of endoscopy (at 10 minutes), at $2 \mathrm{~h}$ they remained statistically significant $(\mathrm{p}=0.003)$ (Fig. 1).

In the other group ( $+\mathrm{G}$ group), the tolerance after 10 minutes was an average of 1.08 in the $\mathrm{CO}_{2}$ group vs. 2.36 in the room air group; after 30 minutes, an average of 1.02 vs. 1.55 respectively; and after 120 minutes, an average of 


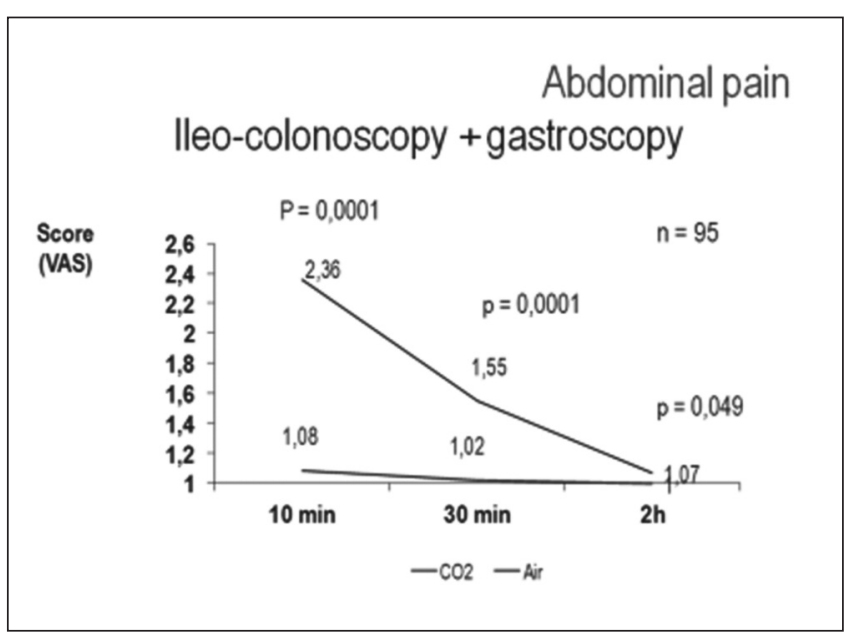

Fig. 2. Abdominal pain in the ileo-colonoscopy + gastroscopy group.

1 vs. 1.07 respectively. All differences were statistically significant $(\mathrm{p}<0.05)$ (Fig. 2).

In terms of increasing abdominal perimeter, in the I group, at the end of the endoscopy, we observed an average of $1.11 \mathrm{~cm}$ in the $\mathrm{CO}_{2}$ group vs. $1.58 \mathrm{~cm}$ in the room air group ( $\mathrm{p}<0.05)$ (Fig. 3). In the $\mathrm{I}+\mathrm{G}$ group at the end of the endoscopy, we observed an average increase in abdominal circumference of $0.81 \mathrm{~cm}$ in the $\mathrm{CO}_{2}$ group vs. $2.07 \mathrm{~cm}$ in the room air group $(\mathrm{p}<0.05)$ (Fig. 4). Also, the difference found in the increase of the abdominal perimeter comparing $\mathrm{CO}_{2}$ and air in the group $\mathrm{I}+\mathrm{G}$ is greater than in the ileocolonoscopy group (Figs. 3 and 4 ).

No complications occurred during the study.

\section{DISCUSSION}

Several studies have shown that $\mathrm{CO}_{2}$ insufflation instead of air during endoscopy can reduce discomfort after the procedure.

Many of the studies published have evaluated the degree of abdominal pain measured by visual analog scale (VAS), at different moments after the colonoscopy. For example, Stevenson et al. (2) published the results of a small study $(\mathrm{n}=56)$, which assessed the effect of $\mathrm{CO}_{2}$ insufflation $v s$. air in abdominal pain after a colonoscopy. A statistically significant difference $(p<0.0005)$ was observed $6 \mathrm{~h}$ after and the day after the procedure $(\mathrm{p}=0.01)$ in the group that used $\mathrm{CO}_{2}$ vs. the air group. Later, Bretthauer et al. (3) showed that $\mathrm{CO}_{2}$ insufflation significantly reduced abdominal pain at the time, $3 \mathrm{~h}, 6 \mathrm{~h}$ and $24 \mathrm{~h}$ after a colonoscopy.

Some authors have postulated that $\mathrm{CO}_{2}$ insufflation may reduce the need for sedation or anesthesia, but few studies have specifically analyzed the effect on sedation. In 2003, Church et al. (5) published the results of a test assessing the degree of abdominal pain immediately after colonoscopy in patients who had used $\mathrm{CO}_{2} v s$. air, showing less abdominal pain 10 minutes after the colonoscopy in

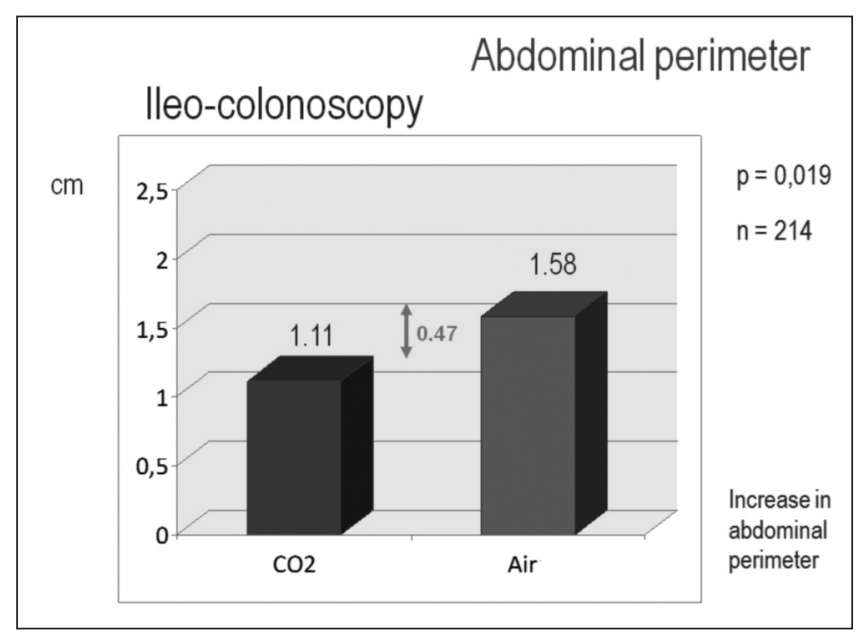

Fig. 3. Increased abdominal perimeter for the ileo-colonoscopy group.

the $\mathrm{CO}_{2}$ group $(\mathrm{p}<0.05)$ but no differences were related to sedation.

The study of Riss et al. (17) evaluated the efficacy of $\mathrm{CO}_{2}$ insufflation after colonoscopy in patients with varying degrees of sedation and, in parallel, the degree of acceptance of screening programs for colorectal cancer (CCR). This study randomized 300 patients to undergo the procedure with $\mathrm{CO}_{2}$ or air, showing less abdominal pain in the $\mathrm{CO}_{2}$ group ( $\mathrm{p}<0.01) 15,30$ minutes and $6 \mathrm{~h}$ after the procedure. But carrying out the analysis according to the level of sedation of patients, we found no differences in the degree of personal satisfaction after the test, or the acceptance of CCR screening programs.

Moreover, given that $\mathrm{CO}_{2}$ insufflation might theoretically involve retention of carbon dioxide and that this retention is favored by sedation (as it may cause hypoxemia and hypoventilation), Bretthauer et al. (6) random-

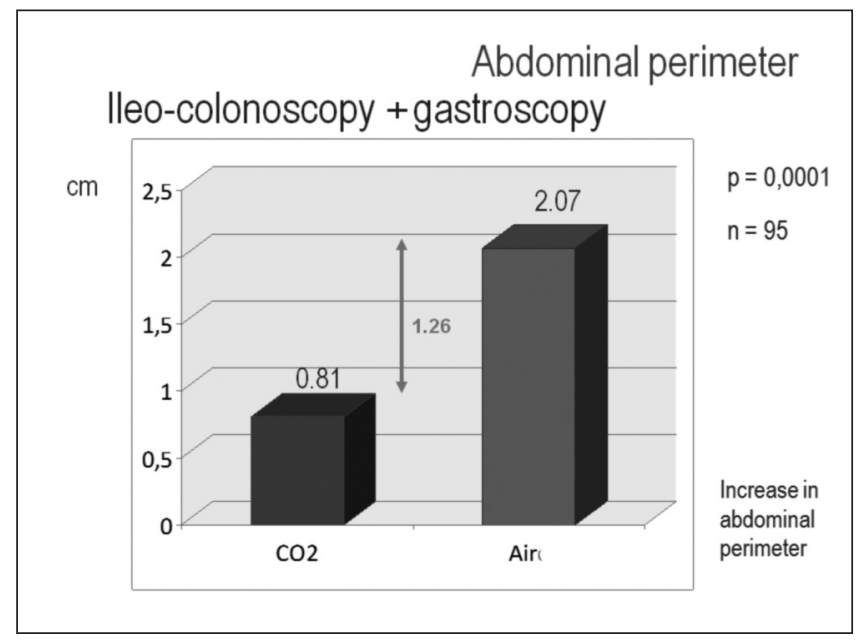

Fig. 4. Increased abdominal perimeter for the ileo-colonoscopy + gastroscopy group. 
ized 103 patients to $\mathrm{CO}_{2}$ or air insufflation in colonoscopy, collecting tidal $\mathrm{CO}_{2}$ levels $\left(\mathrm{CO}_{2}\right.$ ET: End-tidal Carbon Dioxide) before, during and 10 minutes after the procedure. All patients received sedation with Pethidine and Midazolam. Lower degree of abdominal discomfort was observed in the $\mathrm{CO}_{2}$ group compared to the air group, but no statistically significant differences were found in ET $\mathrm{CO}_{2}$ in relation to sedation.

The rate of cecal intubation is an indicator of quality in colonoscopy. Studies have analyzed the colonoscopy exploration mean time using $\mathrm{CO}_{2}$. A double-blind randomized clinical trial published by Yamano et al., in 2010 (7), evaluated the effect of $\mathrm{CO}_{2}$ insufflation in colonoscopy without sedation on the partial pressure of $\mathrm{CO}_{2}$ in the blood $\left(\mathrm{pCO}_{2}\right)$, on the volume of gas pumped, on the abdominal pain, and on the exploration time. They found lower $\mathrm{pCO}_{2}$ levels compared with the reference range and reduced exploration time. They concluded that $\mathrm{CO}_{2}$ insufflation reduces the examination time and enhances the rate of cecal intubation in colonoscopies without sedation. This suggests that the effects of $\mathrm{CO}_{2}$ are more evident in longer explorations.

Another interesting aim in the evaluation of the use of $\mathrm{CO}_{2}$ in endoscopy has to do with the degree of experience of the endoscopist. Some authors argue that cecal intubation rate is higher in more experienced endoscopists (18) and this helps to get better results. In our work it was not necessary to analyze the rate of cecal intubation because it was achieved in all patients included in the study, and ileocolonoscopy was performed in addition. A Japanese group conducted in 2009 a study that evaluated the efficacy of $\mathrm{CO}_{2}$ insufflation in potentially difficult colonoscopies in relation to the level of experience of the endoscopist (18). Overall there was a beneficial effect of $\mathrm{CO}_{2} v s$. air on abdominal pain $(\mathrm{p}<0.001)$ and subgroup analysis showed significantly lower pain score in the group of experienced endoscopist ( $\mathrm{p}=0.023)$.

Our study is the first to analyze the effect of $\mathrm{CO}_{2}$ on abdominal pain and distention after an I and after an I+G. It seemed interesting to assess the effects of $\mathrm{CO}_{2}$ insufflation compared to air for an exploration in which, after a complete colonoscopy, we explored the small bowel and therefore insufflated gas at this level.

We showed that abdominal pain score as well as the increase of abdominal perimeter were significantly lower in patients using $\mathrm{CO}_{2}$ compared to air both in group I and group $\mathrm{I}+\mathrm{G}$.

\section{CONCLUSION}

$\mathrm{CO}_{2}$ insufflation in endoscopic procedures can improve patient tolerance in relation to less abdominal pain and a significantly lower abdominal diameter. The use of $\mathrm{CO}_{2}$ could be indicated in general and especially in long explorations and/or complicated ones, such as performing an ileo-colonoscopy and an ileo-colonoscopy + gastroscopy.
By improving patient tolerance to colonoscopy, we think that $\mathrm{CO}_{2}$ insufflation may improve population adherence to screening programs.

\section{REFERENCES}

1. Bretthauer M, Hoff G, Thiis-Evensen E, Huppertz-Hauss G, Skovlund E. How much gas do we insufflate during colonoscopy? Air and carbon dioxide volumes insufflated during colonoscopy. Gastrointest Endosc 2003;58:203-6.

2. Stevenson GW, Wilson JA, Wilkinson J, Norman G, Goodacre RL. Pain following colonoscopy: elimination with carbon dioxide. Gastrointest Endosc 1992;38:564-7.

3. Bretthauer M, Thiis-Evensen E, Huppertz-Hauss G Gisselsson K, Grotmoll T, Skovlund E, et al. NORCCAP (Norwegian Colorectal Cancer Prevention): a randomized trial to assess the safety and efficacy of carbon dioxide versus air insufflation in colonoscopy. Gut 2002;50:604-7.

4. Sumanac K, Zealley MD, Fox B, Rawlinson J, Salena B, Marshall JK et al. Minimizing postcolonoscopy abdominal pain by using $\mathrm{CO} 2$ insuflattion: a prospective, randomized, double blind, controlled trial evaluating a new commercially available CO2 delivery system. Gastroint Endosc 2002;56:190-4.

5. Church J, Delaney C. Randomized, controlled trial of carbon dioxide insufflation during colonoscopy. Dis Colon Rectum 2003;46:322-6.

6. Bretthauer M, Lynge AB, Thiis-Evensen, E, Hoff G, Fausa O, Aabakken L. Carbon dioxide insufflation in colonoscopy: safe and effective in sedated patients. Endoscopy 2005;37:706-9.

7. Yamano H, Yoshihawa K, Kimura T, Yamamoto E, Harada E, Kudou T et al. Carbon dioxide insufflation for colonoscopy: evaluation of gas volume, abdominal pain, examination time and transcutaneous partial CO2 pressure. J Gastroenterol 2010;45:1235-0.

8. Dellon ES, Hawk JS, Grimm IS, Shaheen NJ. The use of carbon dioxid for insufflation during GI endoscopy: a systematic review. Gastroint Endosc 2009;69:843-9.

9. Rogers BH. The safety of carbon dioxide insufflation during colonoscopic electrosurgical polypectomy. Gastrointest Endosc 1974;20:115-7.

10. Bretthauer M, Hoff G, Thiis-Evensen E, Grotmol S, Thorp Holmsen $\mathrm{V}$, Moritz, et al. Carbon dioxide insufflation reduces discomfort due to flexible sigmoidoscopy in colorectal cancer screening. Scand J Gastroenterol 2002;37:1103-7.

11. Dellon ES, Velayudham A, Clarke BW, Isaacs KL, Gangarosa LM, Galanko JA, et al. A randomized, controlled, double-blind trial of air vs carbon dioxide insufflation during ERCP. Gastrointest Endosc 2010;72:68-7.

12. Bretthauer M, Seip B, Aasen S, Kordal M, Hoff G, Aabakken L. Carbon dioxide insufflation for more comfortable endoscopic retrograde cholangiopancreatography: a randomized, controlled, double-blind trial. Gastrointest Endosc 2007;39:58-4.

13. Domagk D, Bretthauer M, Lenz P, Aabakken L, Ullerich H, Maaser $\mathrm{C}$, et al. Carbon dioxide insufflation improves intubation depth in double-balloon enteroscopy: a randomized, controlled, double-blind trial. Endoscopy 2007;39:1064-7.

14. Hirai F, Matsui T, Yao K, Sou S, Seki T. Efficacy of carbon dioxide insufflation in endoscopic balloon dilatation therapy by using double balloon endoscopy. Gastrointest Endosc 2007;66:526-9.

15. Saito Y, Uraoka T, Matsuda T, Emura F, Ikehara H, Mashimo Y, et al. A pilot study to assess the safety and efficacy of carbon dioxide insuflation during colorectal endoscopic submucosal dissection with the patient under conscius sedation. Gastroint Endosc 2007;65:537-2.

16. Suzuki T, Minami H, Kotmasu T, Masusda R, Kobayashi Y, Sakamoto A, et al. Prolonged carbon dioxide insufflation under general anesthesia for endoscopic submucosal dissection. Endoscopy 2010;42:1021-9.

17. Riss S, Akan B, Mikola B, Rieder E, Karner-Hanusch J, Dirlea D, et al. $\mathrm{CO} 2$ insufflation during colonoscopy decreases post-interventional pain in deeply sedated patients: a randomized controlled trial. The Middle European Journal of Medicine 2009;121:464-8.

18. Uraoka T, Kato J, Kuriyama M, Hori K, Ishikawa S, Harada K, et al. $\mathrm{CO} 2$ insufflation for potencially difficult colonoscopies: efficacy when used by less experienced colonoscopists. World J Gastroenterol 2009;15(Supl. 41):5186-2. 